[DRAFT: THIS VERSION MAY DIFFER IN MINOR WAYS FROM THE PUBLISHED VERSION (IN INQUIRY, APRIL 2009), IN WHICH CASE THE LATTER SHOULD BE CONSIDERED AS AUTHORITATIVE]

\title{
Transcendental Aspects, Ontological Commitments and Naturalistic Elements in Nietzsche's Thought.
}

In what follows I shall focus on Nietzsche's views on knowledge and leave aside such questions as to whether, for example, his understanding of morality should be considered as naturalistic or not. Even from this restricted perspective, the interesting thing about Nietzsche is that he is a particularly tricky case: he has been characterised as a philosopher in the transcendental tradition (Green 2002) and more often as a naturalist and an empiricist (Leiter 2002, Clark 1990 \& 2001, Richardson 2004, and in more nuanced way, Cox 1999). ${ }^{1}$ Prima facie (and perhaps worryingly), there are justifications for both views, in spite of their apparent incompatibility. Thus, Nietzsche has claimed that human experience is necessarily structured according to 'a priori forms' (TL: 87). He has argued for a form of transcendental idealism, making both the ontological assumption that there is a way in which things are in themselves and the epistemological claim that such things are a 'mysterious X' (TL: 83), by definition beyond the scope of human knowledge. Yet in a more naturalistic fashion he also has suggested that philosophy should model its inquiry and method on the sciences, and take into accounts their results. In spite of his disagreement with Darwin on the question of the preservation of life, he has promoted a view of human nature as determined by evolutionary principles. Furthermore, he has rejected both the idea of a Hinterwelt and of the appearances/thing-in-itself distinction, in a way which seems to preclude the dualism inherent to transcendental idealism. And as if endorsing central elements of both naturalism and transcendental philosophy was not tricky enough, Nietzsche also seemingly held a view that denies a central feature shared by these two trends: he apparently rejected the possibility of objective knowledge (his so-called error theory). This has led others (in particular Derrida 1979, De Man 1979, and Kofman 1993) think that he is a proto-deconstructionist, whose purpose is to undermine the ideal of secure knowledge which underlies both naturalistic and transcendental projects.

\footnotetext{
${ }^{1}$ Contrary to Clark and Leiter, Cox takes into account Nietzsche's repeated attacks against science: thus Nietzsche 'uncovers a residual theology in the modern scientific project's claim to describe the way the world really is' (Cox 1999, 6). Cox argues that science must 'overcome itself' into aesthetic discourse, and that such self-overcoming is 'more rigorously naturalistic' (probably in the sense that it is more thoroughly non metaphysical) than the scientific project — a view which presumably neither Clark nor Leiter would be happy to endorse.
} 
The main way to at least reduce the confusion is to look at things chronologically. In this regard, the dominant interpretation (put forward by pro-naturalistic interpreters such as M. Clark and B. Leiter) is that while the early Nietzsche, under the influence of Kant and Schopenhauer, was a transcendental idealist, he soon renounced the mistaken ways of his youth and became a naturalist. To put it simply, the Nietzsche of Truth and Lies believed both in the existence of thingsin-themselves beyond the empirical realm and in their unknowability. Correlatively, this early commitment to transcendental idealism is seen as the main ground for his error theory: since its empirical nature prevents it from capturing the essence of things-in-themselves, all human knowledge is by definition erroneous. Yet from Human All Too Human onwards Nietzsche would have started to have doubts about the existence of things-in-themselves, and ultimately rejected the notion as well as the rather inconvenient error theory it warranted. This would have paved the way for a naturalistic epistemology characterised by his alleged enthusiasm for the sciences, ${ }^{2}$ his emphasis on the continuity between philosophy and science and a 'non metaphysical' commitment to what Clark calls 'common sense realism', i.e. the belief in the existence of mind independent empirical objects (Clark 1993: 61. See chapter 2 in general).

In my view, the problem with this neat reconstruction is that it oversimplifies both Nietzsche's early position and his philosophical development. ${ }^{3}$ The main reason for this is that it implicitly rests on two unwarranted assumptions: firstly, that transcendental idealism can be uncontroversially identified with a two-world view and the strong ontological commitment to the autonomous existence of things-in-themselves it entails; secondly, that being a transcendental idealist in this robust sense is the only way to cash out transcendental claims. ${ }^{4}$ Yet as it is well-

\footnotetext{
${ }^{2}$ There are many other passages, both in the published and unpublished work, which suggest (contra Clark or Leiter) that science does not enjoy any particular epistemic privilege for Nietzsche: thus 'science at its best seeks most to keep us in this simplified, thoroughly artificial, suitably constructed and suitably falsified world (...) - it loves error because, being alive, it loves life' (BGE 24). Or again, 'physicists believe in a "true world" of their own fashion: a firm systematisation of atoms in necessary motion (...). But they are in error. The atom they posit is inferred according to the logic of the perspectivism of consciousness' (WP §636). Perhaps the most lapidary formula is the following one: 'ultimately, man finds in things nothing but what he himself has imported into them; the finding is called science' (WP §606).

${ }^{3}$ Another difficulty, noted by many commentators (in particular Poellner, Cox and Green) is that this reconstruction is not supported by uncontroversial textual evidence, and leaves out the entirety of the Nachlass. Having said that, I should say that in other regards, I am sympathetic to Leiter and Clark's approach, which I have often found illuminating. In particular, I completely agree with Leiter's criticism of the interpretations of Nietzsche that see him as a precursor of post-modernism intent on denying the possibility of any truth and objectivity (cf. Leiter 1994).

${ }^{4}$ There are other, related problems with the naturalistic line of interpretation. Of particular relevance is the fact that it rests on a mistaken definition of transcendental philosophy as 'the search for a priori modes of knowledge which might allow knowledge of the thing-in-itself' (Clark 1993: 68) — along the same lines,
} 
known, deflationary interpretations such as Bird's (Bird 1962) or Allison's (Allison 1983) reject the two-world view in favour of a two-aspect reading which radically minimises the ontological commitments of transcendental idealism in order to emphasise its epistemological ambit, i.e. its attempt to secure the possibility of objective empirical knowledge by identifying its a priori necessary conditions. Interpretations such as Strawson's (Strawson 1966) go even further in this direction by arguing that the best way to bolster this epistemological core is to strip away the ontological commitments entirely. In this paper, I shall suggest that likewise, Nietzsche had a much more nuanced view of transcendental idealism than is attributed to him by his pro-naturalistic readers, and that he too was concerned with prying apart its ontological and epistemological dimensions. By means of a close re-examination of a text central to Clark's own interpretation, namely 'Truth and Lies', I shall establish that his early views about the existence of things-inthemselves are accompanied by a separate analysis of perception which concludes that our experience now has what looks like transcendental conditions ${ }^{5}$ in that it is necessarily structured by

another passage defines 'metaphysical or a priori knowledge as non empirical access to reality and a basis for rejecting the relevance of sense testimony' (Clark 1993: 71)). Yet Kant's ambition was not to reject the relevance of sense testimony, but to show that it is not sufficient, per se, to account for the possibility of knowledge. Moreover, defining transcendental knowledge in this way is tantamount to reverting to a preKantian understanding of the a priori: for Descartes or Leibniz, having a priori knowledge is indeed equivalent to having innate ideas which provide us with non empirically acquired information about such metaphysical issues as the nature of the soul or the existence of God. But as it is well known, Kant was as keen as Hume (although for different reasons) to reject the idea that we could have a priori knowledge of metaphysical essences. More generally, many of the naturalistically inclined Nietzsche interpreters often do not define what they mean by 'transcendental philosophy', nor the ways in which they think it is opposed to naturalism. As a result, the criteria they use to argue in favour of Nietzsche's 'naturalism' are often indecisive, because they would equally well apply to a transcendental philosopher and/or rely on an unsubTL:e view of transcendental philosophy. The reasons for this, I think, are parTL:y historical, and parTL:y due to the context of Nietzsche studies. Thus the rise of naturalism (and of proto-naturalist movements such as materialism in the $18^{\text {th }}$ century or positivism in the $19^{\text {th }}$ century) was mosTL:y targeted at metaphysics rather than at transcendental philosophy. There are traces of this, for example, in the often quoted Quinean definition of naturalism as the rejection of 'first philosophy'. ConsequenTL:y many of the arguments offered in favour of the naturalistic reading of Nietzsche are grounded in his rejection of metaphysics. Correlatively, this antimetaphysical bend is accentuated by the perceived need to oppose interpretations - one of the first and most famous being Heidegger's - which emphasise the resurgence of metaphysical aspects in Nietzsche's thought. However as indicated above Kant was equally distrustful of what he called 'dogmatic' metaphysics. Because they often do not take this into account, the naturalistically inclined readers of Nietzsche, while they have litTL:e trouble showing that he does not want to be a metaphysician, fail to argue convincingly against his being a transcendental philosopher.

${ }^{5}$ By this I mean, in the most general way possible, conditions which a) are non empirical, non causal conditions of possibility; b) are modally necessary and presuppose a normative conception of knowledge, prescribing what must be the case (rather than just describing what is the case) in order for us to be able to know anything; c) consequenTL:y, involve a bid for universality and are governed by a distinctively foundationalist ambition (grounding and thus securing against skepticism the possibility of objective 
'a priori forms' (TL: 87), amongst which time, space, succession and coexistence. These conditions are identified independently from any ontological commitments, through a proto-genealogical study of the evolution of human perception. Given this dual angle, it is no longer possible to conclude, as Leiter and Clark do, that Nietzsche's later revision of his early views about things-inthemselves is tantamount to a rejection of transcendental idealism simpliciter, nor that it results in the elimination of all possible transcendental aspects in his thought ${ }^{6}$. In fact, his reflection on his previous ontological commitments is much more subtle than is usually allowed for: as we shall see, it warrants the passage from a robust to an ultra-deflationary position which establishes the need to remain agnostic about ontological commitments (rather than rejecting them, which per se is another form of robust commitment). Correlatively, Nietzsche's philosophical itinerary can be fruitfully interpreted as a deepening of his early thoughts on the nature of the conditions of possibility of experience, and thus as the development of the epistemological heritage of transcendental idealism.

In a similar way, the so-called error theory is not so easily explained away by Nietzsche's abandonment of his earlier beliefs in the existence of things-in-themselves. As seen by Clark, it does remove one of its grounds, namely the impossible demand for a metaphysical adequation between human knowledge and the essence of things considered in themselves. However TL offers a second, independent argument for the error theory: regardless of any ontological commitments, it infers from the contrast between our current perceptual experience and a different, more primordial form of experience (relegated to a mythical past) that the structuration of the former by a priori elements is in itself a form of falsification. As we shall see, this early claim is developed by later Nietzsche's reflection on the perspectival conditions of life and their relation both to the primal stream of our impressions and what he calls the 'world of becoming'. Unless an alternative interpretation which does not simply rest on Nietzsche's rejection of his early robust ontological commitments is proposed, the error theory will thus remain a serious obstacle to all interpreters (naturalistically and transcendentally inclined) which seek to find in Nietzsche's thought a ground for the possibility of objective knowledge.

Once the complexity of the relation between ontological commitments, transcendental aspects and naturalistic elements in Nietzsche's work is fully acknowledged, new questions arise, on

knowledge). I shall discuss the notion further along in the paper, in particular when examining Nietzsche's naturalisation of the transcendental. 
which I shall focus the second part of this paper: clearly the thrust of Nietzsche's analysis in TL is both to assert the existence of 'transcendental' conditions and to show that they have an empirical genesis, which of course throws their transcendental status into question (hence my use of quotation marks) and attests to the presence of strong naturalistic elements in his thought (in particular because of his Humean insistence on the part played by belief, habit and social practices in the genesis of our 'a priori' forms). So how should we construe Nietzsche's so-called 'naturalisation' of the transcendental ${ }^{7}$, and what are its consequences for the idea of transcendental conditions (in particular, re: their modality and their scope)? Secondly, how do the ontological and epistemological dimensions of transcendental idealism fare in later Nietzsche's work? Finally, and most importantly, is it possible to interpret his error theory in a way that doesn't radically threaten the possibility of his having coherent views about knowledge (be they naturalistic or transcendental)?

Allow me one more remark before I turn to a close examination of these issues: it should be clear from what precedes that my aim in this paper will not be to make a case for Nietzsche being either a naturalist or a transcendental philosopher. I do not think that it is possible to decide either way, let alone to identify, as Clark and Leiter do, an evolution from an early, transcendentally inclined position to a more mature, naturalistic one. For reasons that will appear progressively, I don't even think that one should decide either way. The idea here is rather to examine the interaction of naturalistic and transcendental elements in Nietzsche's thought with a view to identifying nodes of tension, and the way they unfold in his work. As we shall see, such tensions focus mostly on a) the question of whether experience is actively constituted by the mind or passively received through the senses, b) the status of the constituting forms and concepts (a priori or not), c) the problem of whether such a conception of experience requires the existence of a mind independent reality (and if so, how experience relates to the latter), and d) depending on the answers provided to the first three questions, the scope and validity of human knowledge. In the course of examining these tensions, I shall suggest that perhaps the most profitable hermeneutic hypothesis is to see Nietzsche's struggle with them as an attempt to overcome the strict opposition

\footnotetext{
${ }^{6} \mathrm{Cf}$. Clark 1990: 61: 'in fact there is nothing at all transcendental about the position I attribute to Nietzsche. Nothing I attribute to him is out of accord with Rorty's view that "philosophy will have no more to offer than common sense (supplemented by biology, history, etc.) about knowledge and truth"'.

${ }^{7}$ The expression was coined by Stack. However he was mosTL:y interested in showing the extent of Lange's influence on Nietzsche's thought; my own concern is not so much with the history of ideas as with the theoretical implications of such a move, both for transcendental philosophy and naturalism.
} 
between naturalism and transcendental philosophy. It is this third way, with its theoretical benefits and costs, which I want to explore in this paper.

What makes 'Truth and Lies' (henceforth TL) particularly interesting is that it can be seen as a matrix in which most of the strands of Nietzsche's views on knowledge are already present. The text is notoriously complex, and has been the object of numerous interpretations. ${ }^{8}$ While it is obviously an attack against the possibility of universal truth and objective knowledge, what is far less clear is Nietzsche's strategy. The main reason for such complication is that TL constantly intertwines two main lines of argumentation, which both have their source in a reflection on transcendental idealism. On the one hand, and most obviously, Nietzsche infers from the lack of metaphysical correspondence between empirical knowledge and things-in-themselves that our knowledge is 'anthropomorphic' and therefore invalid from a transcendental point of view. As we shall see, per se this is not a particularly good point. Yet on the other hand, there is a more subtle argument: Nietzsche is concerned, not only with what he sees as the failure of human knowledge to adequately capture the in itself, but also with describing the conditions of possibility of experience in a way that remains agnostic about their possible ontological implications. In doing so, he first presents an anti-rationalist view of perception as 'metaphorical': such a view can be interpreted as both anti-Kantian (it rejects the claim that experience is constituted by means of objective judgments) and anti-empiricist (it denies that there is any raw sense data). It then turns out, however, that this view is supposed to describe the way things were experienced in a mythical and forgotten past, and does not reflect the way we perceive anymore. In order to explain the changes in perceptual conditions, Nietzsche offers a fairly Humean description of the ways in which conceptualisation was made necessary by the development of new social practices (the need for truthfulness) and habits. This proto-genealogical account, however, culminates unexpectedly in a quasi-Kantian vision of experience as now shaped by 'a priori forms' (TL: 87). Before analysing the substantial changes the second account brings to the idea of transcendental conditions, I shall endeavour to flesh out and clarify the successive steps of this rather dizzying argument, with a view to bringing out both its transcendental and naturalistic aspects, and their mutual tensions.

\footnotetext{
${ }^{8}$ In particular De Man, Kofman, Clark. While De Man and Kofman read TL: as a deconstructionist analysis of language (as metaphorical), Clark insists holds that the main object of the text is to provide a

Schopenhauerian criticism of representation as fundamentally inadequate to the in-itself. While I agree with Clark that the text should be read as an engagement with transcendental idealism, I do not think that this is its only dimension (cf. main text).
} 
As seen by Clark, TL's attack against objectivity does not rest on an analysis of language, but of perception (thus the metaphors Nietzsche describes are 'perceptual' (TL: 84) and, as we shall see, both pre-verbal and pre-linguistic). The perceptual process is detailed as follows: 'a nerve stimulus is transferred into an image: first metaphor. The image, in turn, is imitated into a sound: second metaphor' (TL: 81). ${ }^{9}$ Per se, there is nothing here that suggests an endorsement of transcendental idealism. Prima facie, the description is pitched at the empirical level and concerns the genesis of representations. As it is very compressed, it is worth looking at into more detail. According to Aristotle (Poetics 1457b), a metaphor is the 'application of a strange term either transferred from the genus and applied to the species, or from the species and applied to the genus, or from one species to another or else by analogy'. ${ }^{10}$ No rules or conditions are specified for such transfer (metaphorein). In the case of a transfer from species to genus (or vice versa) there is clearly a relation of kinship between the two terms considered, but this is not the case when the metaphor links two species 'or else'. By virtue of their analogical nature, metaphors point out a similarity between the two terms considered (although strictly speaking an analogy involves four terms, paired two by two, and concerns the relation between the two pairs rather than the terms themselves). But such similarity is not grounded in an objective consideration of the nature of the objects linked: the connection is subjective, and the resulting judgment, taken literally, would be false. The purpose of such a connection is not to form any knowledge of the objects, but to stimulate the imagination so that it bridges the gap between two terms which per se have little in common, and engages in a free play of significations. Thus Paul Eluard's verse, 'the earth is blue like an orange', does not disclose any objective facts about the earth or oranges. However the metaphor brings to mind aspects in which they could be thought of as similar (such as roundness, natural character, fertility, pitted surface, etc.); the way in which it does this is by sparking an imaginative, almost immediate vision rather than by making us reflect on the nature of the objects (although it is possible, as I have started to do, to articulate after the fact some of the connections established).

How does this apply to perception? Nietzsche's idea seems to be that just as metaphors involve a transfer of meaning from one term to another which does not reflect their objective characteristics so much as the workings of the imagination, in the same way in the case of perception there is no objective, necessary or rational connection between nerve stimuli, images

\footnotetext{
${ }^{9}$ The process is detailed in almost similar terms in a later passage: 'first images — to explain how images arise in the spirit. Then words, applied to images. Finally concepts, possible only when there are words - the collecting of many images in something non visible but audible (word)'. (WP $\S 506,1884$ ).

${ }^{10}$ Trans. H. Fyfe, Cambridge: Harvard UP, 1973
} 
and sounds. They are all different in nature and the passage from one to another is only made possible by the subjective power of our imagination, seen as a primal, artistic power upon which there are, originally, no conceptual constraints. ${ }^{11}$ It has 'no need for [concepts], those makeshifts of indigence' (TL: 90). Thus we are 'artistically creative subjects' (TL: 86) and sounds are the 'coagulation of a mass of images which originally streamed from the primal faculty of imagination like a fiery liquid' (TL: 86). Along the same lines, Nietzsche speaks of the 'drive towards the formation of metaphors' as 'the fundamental human drive' (TL: 88): we are animated by 'an ardent desire to refashion the world (...) so that it will be as colourful, (...) charming, and eternally new as the world of dreams' (TL: 89). As it depends purely on the idiosyncrasies on the perceiving individual, each 'perceptual metaphor' is singular and 'without equal'. This also applies to the 'words' used to convey the images: their assimilation to mere sounds, and the fact that they are distinct from concepts (and do not require the latter for their formation) suggests that this protolanguage is extremely rudimentary. It clearly has no grammar, no logical connectors, no verbs, etc. Each 'word' is likely to be an onomatopoeia functioning like a proper name, associated by further metaphorical transfer to an individual image after the latter has been independently formed by the imagination. Because there are no conceptual constraints on the power of the imagination, neither the images nor the words coalesce into an ordered world of representations, but are 'irregular, lacking in results and coherence' (TL: 89). Correlatively, as there are no common structures for their formation and all perceptual metaphor are private, there is no intersubjectively shared world.

Although it is problematic ${ }^{12}$, such a view is interesting in that it seems aimed both at transcendental and empiricist accounts of experience. It is clearly an attack against the Kantian understanding of experience as dependent on judgments which would bind intuitions into objective representations. For one thing, the formation of images as described here is said not to involve any concepts (as we shall see, for Nietzsche the latter arise from the equalisation of pre-existing perceptual differences), which removes the possibility of judgment as unification of the manifold under a rule. Correlatively, the idea that representations are perceptual metaphors suggests that there is no need for such a possibility anyway: the process can be thought of as purely associative. At one point, Nietzsche claims explicitly that 'metonymy lies at the essence of synthetic judgment' (PT152). Along the same lines, his insistence on the exclusive part played by the imagination in the

\footnotetext{
${ }^{11}$ Later in the text, Nietzsche will offer a proto-genealogy of the empirical reasons why this primal creative power has become constrained, in particular by the need to find resemblances.
} 
formation of representations can be seen as an indirect attack on the notion of schematism. In the first Critique, the role of the imagination is limited to bridging the gap between sensibility and understanding by making sure that our categorial framework can apply to intuitions. ${ }^{13}$ Thus the purpose of the imaginative schemata (as determinate pure intuitions) is to enable the unification of sensory impressions under the rule of the pure concepts of the understanding. Here, Nietzsche lifts such limitations by removing the need for any kind of conceptualisation. ${ }^{14}$ However there are also some strongly anti-empiricist elements in his account. For one thing, most empiricists, although they deny that experience is conceptually united, still grant that it has regularity. Thus for Hume our mental associations are not free: they are regulated, not by a priori concepts or forms, but by psychological principles such as resemblance, contiguity or causality. Yet this is rejected by Nietzsche's insistence on the 'arbitrary' (TL: 82) power of the imagination and the irregularity and lack of coherence of our perceptual metaphors. Secondly both the notion of metaphor itself and the idea that the activity of the imagination is 'primal' suggest that there is nothing which would count as a raw sense datum, passively imprinted on the mind. On the contrary, for something to count as a perceptual content there is need of the interpretative activity of the imagination (which is why the relation between stimulus and image is not merely causal). The very disjunction of the spheres of nervous impulse and image suggests that a pure nervous stimulus could not register on the mind nor become significant for us unless it was interpreted by the imagination. As Nietzsche puts it, a stimulus must be 'seen as red, another as blue', or 'heard as a sound' (TL: 87, my italics). Per se, it is neither blue nor red: it is nothing to us. The 'artistic' power of the imagination thus lies in its ability to transpose nervous stimuli into images which are meaningful for us. ${ }^{15}$

\footnotetext{
${ }^{12}$ Amongst other things, one could argue that it is difficult to understand how 'images' could be formed without any conceptual input. Moreover, it would be difficult to distinguish between two different images if one could not avail oneself to such concepts as coexistence, succession, etc. I shall return to these issues later. ${ }^{13} \mathrm{cf}$. A136/B175 : schematism provides the 'sensible conditions [the schemata] under which alone pure concepts of the understanding can be employed'.

${ }^{14}$ One might be tempted to say that Nietzsche is shifting to an aesthetic perspective, according to which the imagination schematises without concepts. However even the Third Critique requires the existence of a sensus communis, and the postulation that reflective judgments can be universal, two requirements which are clearly not endorsed by Nietzsche's account of perceptual metaphors here.

${ }^{15}$ As we shall see, this anti-empiricist spirit remains present until the end of Nietzsche's work: thus, 'everything of which we become conscious is arranged, simplified, schematised, interpreted through and though' (WP §477, nov 1887-March 1888), or again 'everything that enters consciousness as a 'unity' is already tremendously complex' (WP § 489). However, it should be noted that it sits ill at ease with Nietzsche's anti-conceptualism in his early account of perceptual metaphors. Further along in TL:, and also in his later work, Nietzsche holds that judgment plays a bottom-down part in the formation of experience.
} 
So the first way of understanding Nietzsche's brief comments on the metaphorical nature of perception is to construe them as an independent description which does not rely on any ontological assumptions: it is purely based on an internal analysis of the genesis of our representations which denies the possibility of synthetic a priori judgments without, however, endorsing an empiricist view of experience. Yet Nietzsche immediately (and rather confusingly) shifts the discussion to another, more metaphysically loaded, level: his analysis of perception is now itself taken as a metaphor illustrating the inscrutable relation of human knowledge to what is seen as the essence of things. The focus moves imperceptibly from the idea that the genesis of perceptual experience does not warrant the possibility of objective empirical knowledge to the claim that it is impossible for our representations to correspond to the true nature of things anyway. The argument here is not that objectivity is a priori impossible: it is that even if it was possible (and thus if we could have true knowledge of the empirical world), still our representations would fail to describe the world as it is. We would be in a situation analogous to that of a deaf person contemplating Chladni's figures: seeing the waves produced by sound on sand would get us no closer to understanding what sound is, and would just leave us puzzled. ${ }^{16}$ Thus 'a painter without hands who wished to express in song the picture before his mind would, by means of this substitution of spheres, still reveal more about the essence of things than does the empirical world' (TL: 87). Nietzsche seems to lean towards a phenomenalist view of transcendental idealism ${ }^{17}$, and to claim that there is a radical disconnection between the world of empirical representations and the noumenal world of essences. He suggests two reasons for this: firstly, he rejects the (Schopenhauerian) idea that there could be a causal relation between the thing in-itself and the stimuli we receive: 'the further inference from the nerve stimulus to a cause outside of us is already the result of a false and unjustifiable application of the principle of sufficient reason' (TL: 82). Between appearances and things-in-themselves, as between stimulus and image, there is only a metaphorical, subjectively established relation: 'in the same way as the sound appears as a sand figure, so the mysterious $\mathrm{X}$ of the thing in itself first appears as a nerve stimulus, then as an image, and finally as a sound' (TL: 83). Secondly, even if there was a causal relation between thing-in-itself and appearances, still this would give us no understanding of the thing-in-itself: if we thought so, we would be as mistaken as a deaf person who, having 'discovered the cause [of the sand waves] in

\footnotetext{
16 'Perhaps such a [totally deaf] person will gaze with astonishment at Chladni's sound figures: perhaps he will discover their causes in the vibrations of the string and will now swear that he must know what men mean by "sound"" (TL: 82).
} 
the vibrations of the string', was now to 'swear that he must know what men mean by "sound"' (TL: 83). Nietzsche therefore concludes that 'nature is acquainted with no forms and no concepts, but only with an X which remains inaccessible and undefinable for us' (TL: 83).

This second, better known, line of argument, which is based on the impossibility for human knowledge to apply to the noumenal world, is both close and substantially different from Kant's own position. Clearly, Nietzsche is committed to the ontological thesis that there is a way in which things are in themselves, independently from us, and to the epistemological claim that such things, considered from a transcendental perspective (i.e.: that of the bracketing of epistemic conditions), are by definition unknowable for us. However, the latter was not a problem for Kant's epistemology: the fact that we cannot know anything of the essence of things considered independently of epistemic conditions is a consequence of transcendental idealism, not an argument against the possibility of objectivity in the empirical world. Yet Nietzsche introduces another requirement, that of metaphysical correspondence: he thinks that in order to count as knowledge, our statements must adequately reflect the way things are independently of us. As this is by definition impossible, Nietzsche concludes that human knowledge is necessarily false (the so-called error theory). Like Kant, he is what I shall call an ontological metaphysical realist, in that he thinks that it makes sense to talk of things having an essence independently from the way they appear to us. But unlike Kant, he is a disappointed epistemological metaphysical realist: he thinks that human knowledge should be able to capture the essence of things-in-themselves, and argues from its inability to do so to the radical impossibility of any sort of knowledge, be it empirical or noumenal. The way in which he argues against Kant in the following quote is particularly indicative of his commitment to a (non Kantian) conception of truth as metaphysical adequation: 'there is to be sure a vicious circle here: if the sciences are right, then we are not supported by Kant's foundations. If Kant is right, then the sciences are wrong' (PT §84). What underlies the argument is the assumption that for the sciences to be right is to capture the essence of things considered in themselves. Thus if they are right, their being right is directly grounded by virtue of metaphysical correspondence. One can be a happy metaphysical realist, without any need for transcendental idealism or 'Kant's foundations'. And if Kant is right, i.e. if by definition things-in-themselves are beyond the scope of human knowledge, then the sciences are 'wrong' because they fail to capture the essence of reality. Of course, Kant would say that only if he is right can we be assured that the sciences are right too.

\footnotetext{
17 Thus 'from the very beginning we see the visual images only within ourselves; we hear the sound only within ourselves. It is a big step from this to the postulation of an external world' (PT 144).
} 
The fact that Nietzsche does not see this is indicative of his implicit commitment to metaphysical correspondence, which is the first ground for his error theory.

As should begin to emerge, this second line of argumentation does not seem particularly strong. For one thing, it rests on a misreading of Kant's intentions in the Critique of Pure Reason, and consequently on the sneaking-in of a premise (the metaphysical correspondence requirement) which a proper construal of the critical project would have shown as undesirable. Correlatively, it presupposes an undue generalisation from the impossibility of empirical knowledge to represent the in-itself to the impossibility of empirical knowledge tout court. But it does not follow from the fact that human knowledge must fail the metaphysical correspondence requirement that it must also fail to adequately reflect empirical states of affairs. Moreover, even if one granted the applicability of the metaphysical correspondence requirement to all forms of knowledge, it still would not obviously follow from the transcendental idealist's claim that things or states of affairs are unknowable from a transcendental perspective that empirical knowledge could not correspond to things as they are in themselves, although of course there would be no way we could know that such a correspondence exists, let alone ground it. In other words, our knowledge could happen to be metaphysically true (in an adequationist sense), although we could not justify why it is true. As it is well-known, this is a particularly thorny issue in Kant studies (the so-called neglected Trendelenburg alternative). Nietzsche himself is aware of this possibility, and actually criticises Kant twice for having excluded it: thus 'against Kant, it must be further objected that even if we grant all his propositions, it still remains entirely possible that the world is as it appears to us to be' (PT §84). Equally, 'we should not presume to claim that this contrast [between individual and species] does not correspond to the essence of things: that would of course be a dogmatic assertion and as such, would be just as indemonstrable as its opposite' (TL: 83-84). Nietzsche thus rebukes Kant for not having been critical enough: he should have seen that the claim that empirical knowledge cannot correspond to metaphysical states of affairs is an unwarranted synthetic a priori judgment. ${ }^{18}$ Yet strangely enough, he does not seem to be aware that the criticism would apply

\footnotetext{
${ }^{18}$ There are ways of at least trying to make the claim good, in particular Allison's argument that it follows analytically from Nietzsche's considerations about space and time being conditions of possibility of representation that they cannot apply to the things-in-themselves, and that therefore the claim that thingsin-themselves are not spatio-temporal is not synthetic but analytic. But as Nietzsche himself does not consider the issue, and seems to endorse the Trendelenburg alternative, I shall leave this issue aside.
} 
equally well to his own falsification thesis, and that by the same token, he is unjustified in claiming that our knowledge necessarily fails to capture any features of things-in-themselves. ${ }^{19}$

At this point, it might be useful to summarise our findings, with a view to identifying the play of transcendental and naturalistic elements in the early Nietzsche's thought. I have suggested that he has two distinct arguments against the possibility of objectivity: the first one concerns the genesis of representations and is highly ambiguous in that it combines both anti-transcendentalist and anti-empiricist aspects. The second rests on his endorsement of a robust form of transcendental idealism and of the non Kantian requirement of metaphysical correspondence. However, we are not at this point in possession of all the elements in the picture, and must therefore consider the additional arguments offered by Nietzsche in TL before drawing any definitive conclusion.

Temporarily leaving aside the issue of metaphysical correspondence, Nietzsche returns to his analysis of the genesis of representations, but this time from a diachronic perspective. The new and important element is that his former analysis of perception as metaphorical is now recontextualised within a genealogy which acknowledges that conceptualisation is now needed, and tries to explain why. Nietzsche is concerned with showing the ways in which our imagination, while originally unconstrained, has progressively been forced to operate in a fixed manner. This pre-genealogical account is distinctively Humean in that it insists on the part played by social needs and habits in the process, and thus provides naturalistic reasons for the taming (and the forgetting) of our 'primal' metaphorical power. Starting from the implicit premise that it is necessary for human beings to live in society (presumably for Rousseauist reasons having to do with the scarcity of natural resources and the natural vulnerability of the species), Nietzsche's account is developed in the following steps: a) for social order to be possible, there is a need for its members to be able to

\footnotetext{
${ }^{19}$ In Nietzsche's defence, it could perhaps be said that even if our statements happened to correspond to the in-itself, the very conditions under which the problem is set would prevent them from counting as knowledge. Interestingly, the situation evoked here seems to anticipate on the Gettier problem: as it is well known, one of Gettier's examples is that of someone who, upon seeing a robot-dog on a lawn, says: 'there is a dog over there'. As the perceived dog is not a real dog, the statement is false (although justified), and thus cannot count as knowledge. Gettier then introduces the additional premise that there is a real dog behind the robot dog, hidden from the speaker by a bush. Gettier's conclusion is that although the statement then would turn out to be true, it would still not count as knowledge. In the same way, it could perhaps be argued (although Nietzsche doesn't) that if our statements, which are deemed by Nietzsche empirically false because of the lack of metaphysical correspondence and thus are not considered as items of knowledge, turned out to be metaphysically true, but for reasons which are unavailable to us, they still could not count as knowledge. It would just be a case of epistemic luck.
} 
be truthful. It is a 'duty which society imposes in order to exist'20 (TL: 84): otherwise it would be threatened with chaos and could not maintain itself; b) 'to be truthful means to employ the usual metaphors' (ibidem), i.e. (for Nietzsche) concepts, presumably so that statements are communicable, ${ }^{21}$ verifiable and justifiable. If there was no common reference, or no stability in the relation between meaning and reference, then no societal life would be possible; c) yet such concepts are themselves deemed false, by virtue of the process of abstraction whereby they are obtained; d) consequently, we have the 'duty to lie according to a fixed convention, to lie with the herd and in a manner binding on everyone' (TL: 84).

Clearly, a lot hinges on step c). What is the ground for saying that conceptualisation is necessarily a form of falsification? And what exactly is being falsified? Two main reasons can be inferred from Nietzsche's text. The first one is that conceptual knowledge fails to fulfil the metaphysical correspondence requirement. This is probably Nietzsche's weakest argument in that it is the least specific (it would apply equally to the primal stream of metaphors): from this perspective, it is difficult to see why fixed metaphors would be, as Nietzsche clearly thinks they are, worse than unfixed ones. The second reason is reminiscent of the empiricists' criticism of the formation of abstract ideas: it is the claim that concepts are formed a posteriori, through an impoverishment of the original perceptual metaphors. The process can be detailed in two steps: firstly, the original, singular images are 'universalised (...) into less colourful, cooler concepts, so that [man] can entrust the guidance of his life and conduct upon them' (TL: 84). Such universalisation is in turn made possible by the forced equalisation of individual differences. Thus whereas 'each perceptual metaphor is individual and without equals and is therefore able to elude all classification' (TL: 84-5), 'every concept arises from the equalisation of unequal things: just as it is certain that one leaf is never totally the same as another, so it is certain that the concept 'leaf' is formed by arbitrarily discarding these individual differences' (TL: 83). ${ }^{22}$ Secondly, we forget about this genesis and take concepts to refer to real entities in the world. Thus the formation of universals,

\footnotetext{
${ }^{20}$ The reference to 'duty' in this context could be seen as ironically reminiscent of Kant's arguments both in the Groundwork in 'Of the so-called right to lie'. Polemically, Nietzsche sees the empirical origin of what Kant understands as an a priori moral duty in the need for social order and cohesion.

${ }^{21} \mathrm{Cf}$. WP §569: 'communication is necessary, and for there to be communication something has to be firm, simplified, capable of precision (above all in the so called identical case). For it to be communicable, however, it must be experienced as adapted, as "recognisable". The material of the senses adapted by the understanding, reduced to rough ouTL:ines, made similar'.

${ }^{22}$ Nietzsche presupposes that our ability to distinguish different objects is non conceptual: yet one could argue that in order to identify a leaf as such in the first place (and thus to be able to tell two leaves apart) one already needs the concept of a leaf, and therefore that it is presupposed by the very process of which it is described as result.
} 
conjoined with the arbitrary singling out (the 'arbitrary assignment', TL: 82) of general properties such as 'green' which are implicitly referred to substances as their bearers, gives rise to the illusion of a world of mind independent empirical entities: thus we 'proceed from the error of believing that we have these things immediately before us as mere objects. We forget that the original perceptual metaphors are metaphors and take them to be the things themselves' (TL: 86). There is therefore a double falsification at play: firstly, the original individual perceptual metaphors are solidified into concepts; secondly, this process is forgotten and we become naïve realists, believing in the independent existence of entities picked out by these concepts. Although Nietzsche does not say it explicitly, presumably this allows for the attribution of a truth value to our statements, since such entities can then serve as reference and thus make it possible to verify our statements.

This is the first appearance of a theme (namely that concepts, and therefore conceptual knowledge, necessarily falsify) which offers a second ground for Nietzsche's error theory. Note that, like his first views about the metaphorical character of perception, it is independent from his commitment to transcendental idealism, and that therefore it will not be affected by his ulterior rejection of the thing-in-itself. Because of its importance, it is worth examining this early version of the conceptual falsification thesis in a little more detail. Perhaps the first thing to say that for all its apparent simplicity, it is deeply ambiguous in that the nature of the falsified varies implicitly: in the quotes given above, Nietzsche first identifies it with 'each original perceptual metaphor', but then goes on to say that 'every concept arises from the equalisation of unequal things' (my italics). The example of the leaf confirms that he is now talking about the equalisation of the differences between various entities, not perceptual metaphors (thus he talks about it being certain that 'one leaf [ not a perceived leaf] is never totally the same as another'). In the same way, his criticism of our picking of properties as arbitrary presupposes a similar realist view of the falsified: thus 'we speak of a "snake": this designation touches only upon its ability to twist itself and could therefore also fit a worm' (TL: 82). This would suggest that Nietzsche himself occasionally falls prey to the illusion he criticises, namely that of the belief in the existence of mind-independent entities which pre-exist our perception of them. ${ }^{23}$

Given the general focus of his argument in TL on perceptual metaphors, let's assume that what Nietzsche really means here is that concepts falsify our original imaginative metaphors. In this case, the falsification thesis assumes not only that we have from the start the ability to form many

\footnotetext{
${ }^{23}$ I shall return to this point, and suggest an interpretation of the development of the error theory as a warning against precisely this illusion, rather than against the possibility of knowledge in general.
} 
perceptual metaphors, but that such metaphors can be said to differ from one another. Otherwise, the idea of original 'singular' images would make no sense, and nor would that of a subsequent conceptualisation as equalisation of differences in perceptual content - all we would have is a stream of undifferentiated perceptions which thus could not be individuated enough to be falsifiable. But Nietzsche is clear that each perceptual metaphor is 'a unique and entirely original experience' (TL: 83). Then the question arises of whether we are originally aware that our perceptual metaphors are different from each other (as opposed to just having different perceptual metaphors). Nietzsche is not clear on this matter, but it seems that there are two possibilities. Firstly, if the equalising process of conceptualisation is seen as conscious and intentional, then it does require that each perceptual metaphor should be perceived as different from the others from the start. Otherwise it simply would not be possible to compare them in order to form the smallest possible common denominator (the concept). In this case, the existence of such awareness reinforces the anti-empiricist aspect of Nietzsche's account of perception in the sense that the perception of difference as such cannot be accounted for by merely having different perceptual metaphors. ${ }^{24}$ Yet by the same token, one could argue (along Kantian lines) that the idea that it is possible to differentiate thus between perceptual particulars without any conceptual input at all is dubious. It would seem that in order to have a sense of difference, one needs a minimal conceptual framework, including such general concepts as, for example, quantity, unity or succession.

Otherwise perceptual metaphors would merge into one another and be undistinguishable. This picks up on a problem I flagged earlier, namely the idea that it is difficult to understand how the imagination could, without the use of any concepts, have the formative and individuating activity that Nietzsche attributes to it. Although their content may not be fully articulate, the original perceptual metaphors could not stand as distinct 'images' without the use, at least of categorial concepts.

One way out of this problem is to move to the second possibility alluded to above, and to construe the equalising process that results in the formation of concepts as unconscious. In this case there would be no requirement for us to be aware of the differences between perceptual metaphors. Motivated by social need, we could simply react insensibly to such differences in a manner which progressively reduces them so that we end up with conceptually structured and thus communicable representations. This would be a fully naturalistic account of the formation of concepts, in line with

\footnotetext{
${ }^{24}$ As it is well known, Kant make a similar objection to Hume about succession: having a perception of succession, as we clearly have, is not reducible to having successive perceptions.
} 
Nietzsche's insistence on the role of habit and need in their genesis. However it sits uneasily with his non empiricist account of the part played by the imagination in the formation of perceptual metaphors, and also with other claims which suggest that the formation of the conceptual edifice was intentional, deliberate and conscious. ${ }^{25}$ Furthermore, if there was no awareness of the difference in perceptions from the part of the perceiver, then it is difficult to determine the perspective from which they could legitimately be said to have been different. The claim can only be made from the third person, from the point of view of the philosopher (Nietzsche) who retrospectively identifies the differences in perception and diagnoses the equalisation. But how can he be assured that such identification is legitimate, and that there really were differences in the first place? Not only is he describing a long gone, mythical past, which he says has been 'forgotten' (TL: 84,86 ); he is also assuming that it is possible to describe a first person experience (having the different perceptions, although without being aware of their differences) from a third person perspective, which is made problematic by the private character of such perceptions. ${ }^{26}$ It could be argued that he is relying on an analogy between his current perceptions and the ones attributed to the original, pre-conceptual humans. But he is clearly highly aware of perceptual differences. Moreover, the simple act of describing the process would transform the original experience, if there was one. So both the language of the description and the way in which Nietzsche experiences the world are now incompatible with the primitive experience he is trying to describe. In such a case, it becomes difficult to provide any argument for the claim that there was a difference in perceptual content which would have been unconsciously equalised, because it is impossible to establish the truth of the premise. At best the whole reasoning can be seen as hypothetical, which is not the modality of Nietzsche's speech (it is assertoric).

So Nietzsche's original two lines of argumentation, namely his characterisation of experience as 'perceptual metaphor' and his endorsement of transcendental idealism joined with the non Kantian requirement of metaphysical correspondence, are now complemented by a protogenealogical account of the ways in which conceptual use has become necessary. This seems to culminate in a rather Humean vision of experience: 'even the relationship of a nerve stimulus to the generated image is not a necessary one. But when the same image has been generated millions of times and has been handed down for many generations and finally appears on the same occasion

\footnotetext{
25 'Man now places his behaviour under the control of abstractions. He will no longer tolerate being carried away by sudden (...) intuitions. First he universalises all these impressions into less colourful, cooler concepts, so that he can entrust the guidance of his life and conduct to them' (TL: 84, my italics).
} 
every time for all mankind, then it acquires at last the same meaning for men it would have if it was the sole necessary image and if the relationship of the original nerve stimulus to the generated image were strictly a causal one' (TL: 87). Having forgotten both the part originally played by the imagination in the formation of perceptual metaphors and the reductive process whereby concepts where acquired, we have 'convinced ourselves of the eternal consistency, omnipresence and infallibility of the laws of nature' (TL: 87). Prima facie, both the genealogy and its conclusion seem to reinforce the naturalistic elements in Nietzsche's thought. However, they unexpectedly result in a substantially different and much more transcendentally inclined account of the way experience is structured now, i.e. at the end of the historical process described in TL.

The main difference is this: whereas before Nietzsche denied the need of any kind of a priori framework constraining the formation of perceptual metaphors, he now states that 'the artistic process of metaphor formation with which every sensation begins in us already presupposes [these] forms and thus occurs within them'(TL: 87, my italics). Such forms are identified as 'time and space, and therefore relationships of succession and number'27 (TL: 87). Other passages specify that 'space, time and the feeling of causality appear to have been given along with the first sensation'(PT §80, my italics), or again that 'the perceived manifold already presupposes space and time, succession and coexistence' (PT §140, my italics). Two things are worth noting: firstly, such claims set Nietzsche even further apart from an empiricist account of the formation of experience in that they implicitly reject the idea of a tabula rasa. While experience does rely on some form of sensory input, it also requires the existence of a priori elements. Each time we experience something, the forms are 'already' there, 'given along with the first sensation'. The forms do not cause the sensations (as we have seen, for Nietzsche it cannot even be said that nervous stimuli do). Correlatively, their anteriority is not chronological (it would make no sense to say that the forms exist before experience as such relations of anteriority or posteriority can only be defined from the perspective of experience, i.e. from within the framework provided by such forms). Although they can be defined in isolation, they do not pre-exist experience, or exist independently from it. Nietzsche seems to think that they shape such experience (as opposed to experience merely happening in conformity with them): thus, because of them we 'bring to things' their properties (TL: 87). This may implicitly motivate (or at least reinforce) his claim that the world as we perceive

\footnotetext{
${ }^{26}$ Remember that in this hypothesis, there is no conceptual element in perception and no common language to provide such perceptions a public character.

${ }^{27}$ (possibly an implicit reference to the Axioms of Intuition, the Anticipations of Perception and the Analogies).
} 
it cannot be the world of things-in-themselves, and thus that human knowledge by definition fails the metaphysical correspondence requirement. Secondly, Nietzsche does not seem to distinguish strongly, as Kant does, between the a priori forms of sensibility and the pure concepts of the understanding: time, space, causality, coexistence and succession (neither of the last two being, strictly speaking, categories) are placed on an equal footing. This may be partially due to Schopenhauer's influence (since the latter included causality, along with time and space, in his definition of the principle of sufficient reason). It may also indicate that in fact, Nietzsche does not think that it is possible to consider sensory content independently from some form of conceptualisation (we have seen that this was a problem for his view of perceptual metaphors as relying purely on the imagination). Yet such conceptualisation should not be seen as requiring a full blown, verbal and consciously articulate use of concepts. By placing causality, existence and succession on the same level as time and space, Nietzsche seems to hold that perception requires minimal ordering, which cannot be provided by time and space alone. We have to be able to judge that some impressions happen after others in time, or coexist with them in space. As we shall see, this anti-empiricist aspect is reinforced in the later work.

Yet although they look transcendental in the Kantian sense, the conditions identified by Nietzsche are not truly so. The point of his genealogical account is to show how they have been acquired, and how the way we perceive the world consequently changed. Thus by opposition to the time when our imagination ran free, we are now 'forced to comprehend all things only under these forms' (TL: 87, my italics). Moreover, Nietzsche’s proto-genealogy indicates that since conceptualisation arose from need and was enforced by habits and forgetfulness (both of the singularity of the original perceptual metaphors and of the part played by the imagination), there is no rational validation for the necessity of these forms: 'we produce these representations [of time and space] in and from ourselves with the same necessity [i.e. presumably, natural necessity] with which the spider spins'(TL: 87). The 'transcendental' elements in perception have an empirical genesis: they have their causal conditions of possibility in the rise of new practices (such as societal life), and their necessity is only relative to these practices. Thus although Nietzsche's account of the current way we experience the world is certainly not empiricist, it is not truly transcendental either. In order to bring out its specificity, it may be useful to refer to Mark Sacks' distinction between transcendental constraints and transcendental features (Sacks 2003: 211-218). The first indicates a 'dependence of empirical possibilities on a non-empirical structure" (Sacks 2003: 213). In such a case, the conditions of the constitution of experience are definable in isolation and in 
anticipation of what they determine (in the way the transcendental organisation of the faculties can be spelled out completely independently of experience in Kant, and in such a way that experience must conform to them). This makes it possible, at least in theory, to secure the possibility of objective knowledge completely, i.e. in a universal way. It would not make any sense to think of a change in transcendental constraints which would result in a change in experience; on the contrary, they are what allows us to think the possibility of succession (and thus of change) and to identify it in the empirical world. By contrast, transcendental features indicate the limitations implicitly determined by a range of available practices (...) to which further alternatives cannot be made intelligible to those engaged in them' (Sacks 2003: 213). To claim that such features exist is to reject the empiricist (or naturalist) view that experience is the result of purely associative processes which ultimately depend on physical causes (such as changes in the environment, or in the neurophysiology of the brain). This accounts for their 'transcendental' aspect: they operate like transcendental constraints in that they delimit the structure that experience has to conform to in order to count as experience. Yet they can only be considered a priori from an artificially induced synchronic perspective, if one looks at experience at an instant $\mathrm{T}$ and inquires, in a decontextualised way, about the necessary structure of such experience. Ultimately they must be replaced within a diachronic account (in this case, Nietzsche's proto-genealogical project) which shows that their genesis is dependent on changes in empirical practices (such as the apparition of the need for truthfulness in TL). Thus contrary to constraints, transcendental features can only guarantee the possibility of objectivity in a limited way, within the context of a certain range of practices. If the practices change, so will the transcendental features which ultimately are 'no more than a shadow of necessity cast by whatever practices are current' (Sacks 2000: 213). This, it seems, pretty much captures the spirit of Nietzsche's view: there are some apparently non empirical conditions for knowledge, but these are ultimately dependent on empirical circumstances. On the one hand, philosophy must 'bring to light the preconditions upon which the process of reason depends' (WP $\S 487$ ), such as the 'categories', 'Euclidean space' (WP §515) or the 'a priori law of causality' (KSA 25 $=\mathrm{W}$ I 1. Spring 1885. 26 [74] ${ }^{28}$. Such preconditions work in a transcendental way insofar as their validity cannot be verified by empirical means (since such proof would presuppose their use), and because it is impossible to identify them with any particular set of practices (thus although TL suggests that they appeared along with new practices, they are not identical to these practices). Yet on the other hand, 'the mode under which we know and form knowledge is already itself part of

\footnotetext{
${ }^{28}$ (all the translations from the Nachlass are mine)
} 
our conditions of existence: but (...) this factual condition of existence may be only fortuitous and not necessary at all' (KSA: 25 = W I 1. Spring 1885. 26 [127], my translation. The first set of italics is mine, the others, Nietzsche's). Correlatively, such conditions are not rationally justified but grounded in belief: their necessity is psychological, and the truths that they provide are only 'conditional' (WP §515).

So while both Nietzsche and Kant are transcendentally inclined in that they have a non empiricist view of experience and agree that it necessarily presupposes the use of a spatio-temporal and conceptual framework, Kant sees the latter as a constraint, and Nietzsche as a feature. This has two consequences: firstly, it makes it even more difficult to tell whether Nietzsche should be seen as a naturalist or a transcendental philosopher. The reason is that there is an intrinsic instability (or reversibility) to the notion of transcendental features: their existence can equally be seen as an argument for the transcendental philosopher (in that the constitution of experience conforms to a priori elements which are not accountable for through empirical psychology or neurophysiology) and for the naturalist (in that such elements are not a priori in the strong sense of constraints, as they ultimately depend on contingent practices which could themselves be accounted for in a naturalistic way, especially if one is a 'soft' naturalist). One can insist either on the anti-empiricist thrust of such an account of experience, or on the fact that the a priori, being empirically rooted, is neither universal nor necessary in the non causal, non psychological manner required by transcendental constraints. Furthermore, Nietzsche’s proto-genealogy suggests both that the possibility of knowledge is contingent on the existence of a specific framework, and that such a framework is revisable if the conditions of experience change (and, in fact, has already been revised), something a true transcendental philosopher would not accept. Secondly (and correlatively), a similar ambiguity carries over to the relation between transcendental features and objectivity. The advantage of a transcendental approach over a purely empiricist or naturalist one is that if it succeeds, it can guarantee a priori the possibility of an agreement between experience and its objects. On such an account, experience can stop (or not happen) but not fail to conform to its a priori conditions. The possibility of such conformity is preserved by the notion of transcendental features, but in a much more limited way: they guarantee that at a given time, and under certain empirical conditions, there will be harmony between the conditions under which we know and the structure of the objects we can know. But should the empirical context change, other forms of knowledge and other objects will appear (thus in TL, causally related spatio temporal objects by opposition to the original perceptual metaphors). Objective knowledge is now possible, but it isn't 
truly universal. Whereas the singular and randomly formed character of perceptual metaphors made it impossible for our representations to be regulated by any rules and for us to have a shared perceptual world, now the use of both a priori forms and concepts can in principle guarantee the possibility of a agreement between the conditions under we perceive and the perceived world. Nietzsche is well aware of this: 'all that conformity to law, which impresses us so much in the movement of the stars and in chemical processes, coincides at bottom with those properties which we bring to things' (TL: 87). Or again, 'in all things we comprehend nothing but these forms. For they must all bear within themselves the laws of number' (TL: 87). Yet because of his commitment to transcendental idealism and to the metaphysical correspondence requirement on the one hand, and of the falsification thesis on the other, this tentative opening for objectivity aborts immediately: thus 'we presuppose that nature behaves in accordance with such a concept. But in this case first nature and then the concepts are anthropomorphic (...). The essence of things does not correspond to this: it is a process of knowledge which does not touch upon the essence of things' (PT 150). But should his commitment to ontological metaphysical realism and his error theory disappear, this would leave in principle leave some scope for a relativised form of objectivity within the framework of naturalised transcendental features.

I now want to look at the ways in which the themes set in place by TL develop both in Nietzsche's middle and late period. As previously, what interests me most is the interaction between naturalistic elements, transcendental aspects and their ontological assumptions. I shall therefore focus on three main issues: a) Nietzsche's alleged rejection of transcendental idealism and the sort of ontological commitments (if there are any) that follow from it, b) his reinterpretation of transcendental features as perspectival 'conditions of life' and c) whether it can be rescued from the threat posed by the error theory.

As pointed out by Clark and Leiter, from $\mathrm{HH}$ onwards Nietzsche seems increasingly distrustful of ontological claims, and presents two distinct arguments: firstly, in a quasi Allisonian way he identifies the possibility of the existence of a noumenal realm as the analytic correlate of the notion of perspectival conditions. Thus, 'it is true, there could be a metaphysical world: the absolute possibility of it is hardly to be disputed. We behold all things through the human head and cannot cut off this head; while the question nonetheless remains of what of the world would still be there, if one had cut it off [i.e.: if epistemic conditions were bracketed]' (HH I: $\S 9$, my italics). Yet Nietzsche argues that although such existence can be legitimately conceived, it is of no importance 
whatsoever to us because by definition we cannot know anything of such a world which would make a difference to our lives: 'one could assert nothing at all of the metaphysical world except that it was a being-other, inaccessible, incomprehensible being-other; it would be a thing with negative qualities. (...) Knowledge of it would be (...) more useless even that the knowledge of the chemical composition of water must be to the sailor in danger of shipwreck' (HH I: §9). Thus Nietzsche seems to implicitly move from a robust interpretation of transcendental idealism to a more deflationary one, focused on the noumenon as a purely negative concept, and then to make the further, pragmatic point that we shouldn't concern ourselves with such a possibility because it is irrelevant to us. The underlying idea seems to be that while the robust interpretation of transcendental idealism did matter because of its nefarious moral implications (and thus had to be rejected), this deflationary view can stand because it is so empty as to be harmless. To this argument, Nietzsche adds a second, more ambiguous one: 'as though knowledge here got hold of its object purely and nakedly as the 'thing-in-itself', without any falsification on the part of either the subject and the object! But (...) the "thing-in-itself" involve[s] a contradiction in adjecto'(BGE I §16, Nietzsche italics). The first part of the quote suggests that the idea that we can know the thing-in-itself is contradictory (which certainly follows from its concept, unless such knowledge is inferred analytically from the definition of such a thing); but the conclusion suggests that it is the very notion of a thing-in-itself which is contradictory. Clark develops the contradiction as follows: 'we can have no conception, or only a contradictory one, of something that would be independent of all knowers, and therefore of all conceptualisation, because to conceive of something is to conceive of it as satisfying some description or other, which is to think of it as being conceptualisable in some way or other' (Clark 2000: 46-7). Yet this gloss only works at the cost of introducing implicitly a different conception of the thing-in-itself than the one indicated in $\mathrm{HH}$. There Nietzsche suggested that the metaphysical world is merely the correlate of the bracketing of the transcendental features that are relevant to us (what remains if one 'cuts our head off'), not of the bracketing of any epistemic conditions. To recast this in his later vocabulary of perspective, the first idea is that things-in-themselves are things considered independently of our perspective; yet a contradiction in adjecto can only be made good if things-in-themselves are thought of as entirely extra-perspectival. Only then does it become possible to argue, as Clark does, that the very existence of the definition presupposes that of a perspective from which it originates, and therefore that there is a latent contradiction between the definiens and the nature of the definiendum. 
Prima facie, later Nietzsche makes a move of that sort when he claims that a 'thing' (both in its traditional sense, as substance, and in its more Kantian understanding as thing-in-itself) is nothing more than 'the sum of its effects (WP §551). According to this logic, 'the "thing in-itself" is indeed nonsensical. If I remove all the relationships, all the properties, all the activities of a thing, the thing does not remain over' (WP §558). As pointed out by Poellner, it is dubious whether this argument would truly apply to Kant ${ }^{29}$; at any rate, it is clearly designed to deny the possibility of strong metaphysical ontological realism by invalidating the claim that there is a way in which things are in themselves. Thus 'the in-itself' is even an absurd conception: a "constitution in-itself" is nonsense; we possess the concept "being”, "thing”, only as a relational concept' (WP §583). However, it does not follow from this that it would make no sense to ask again, as Nietzsche himself did in $\mathrm{HH}$, whether some $\mathrm{X}$ would remain if our perspectival conditions were bracketed. Although the idea that such X could have a self-standing essence, definable independently from any perspective, has just been rejected, and although we couldn't say anything positive about it, there could be other perspectives from which such an X could be considered. Very interestingly, it is this very possibility that a passage from the Gay Science considers, in terms which are strikingly similar to those of $\mathrm{HH}$ : 'how far the perspective character of existence extends or indeed whether existence has any other character than this (...) — that cannot be decided even by the most industrious and most scrupulously conscientious analysis and self examination of the intellect: for (...) we cannot look around our own corner. (...) But I should think that today we are at least far from the ridiculous immodesty that would be involved in decreeing from our corner that perspectives are permitted only from this corner' (GS V §374). Thus the critical project (the 'scrupulously conscientious ... self examination of the intellect') can only carry us to the limits of our own perspective: we cannot transcend the conditions by which our experience is structured. However such a critique also reveals that our perspective is not the only possible one, although it is the only one which we can understand. Thus 'let's say that [what 'we believe in most, all the a priori'] presents itself as a condition of existence for our species - a sort of fundamental hypothesis. This is why other beings could make other hypotheses, four dimensions for example' (KSA 25 = W I 1 . Spring 1885. 25 [307]). It is conceivable that there could be a plurality of perspectives, each with its own kind of a priori conditions (thus 'some beings might experience time backwards, or alternatively forward and backward', GS V §374), which are incommensurable: 'it is likely that there are numerous kinds of intelligences, but each has its own laws which make it impossible for it

\footnotetext{
${ }^{29}$ (Poellner 2001: 96 note 20).
} 
to represent another law' (KSA M III 1. Spring-autumn 1881 11[291]). The existence of these other perspectives is enough to warrant a minimal ontological commitment to the possibility of there being some $\mathrm{X}$ considered independently from us, but not from any perspective. Most importantly, however, Nietzsche does not say that there is such an X, only that perspectivism allows us to conceive of such a possibility. Thus his position in his later work is more subtle than is usually allowed for: although he rejects the notion of things-in-themselves as over-determined, he does not make the (equally strong) claim that if the conditions that structure our experience were bracketed, nothing would remain. By contrast, his criticism of the thing-in-itself and the fact that he acknowledges the possibility of a plurality of perspectival conditions (as opposed to single, universal constraints) lead him to remains agnostic about ontological commitments. Importantly, this removes one of the grounds of his error theory: if whatever remains if our epistemic conditions are bracketed has no 'constitution in-itself', then metaphysical correspondence cannot be a requirement. ${ }^{30}$

This subtle reflection on the ontological commitments of transcendental idealism is accompanied by a deepening of Nietzsche's understanding of transcendental features, now reinterpreted as part of the perspectival conditions that make possible human experience and life. ${ }^{31}$ Thus 'the belief in the truth [of synthetic a priori judgments] is necessary, as a foreground belief and visual evidence belonging to the perspective optics of life'(BGE I §11, my italics). The existence of transcendental features is the reason why although each empirical individual's particular perspective may vary depending on this individual's idiosyncrasies, interests and situation, all the objects that are singled out by human perspectives will share a few common, structural traits — in particular, being spatio-temporal, having an objective order of succession, being interconnected by the law of causality. ${ }^{32}$ Yet just as in his early work, Nietzsche seems uneasy with this idea. This dissatisfaction is expressed by the many statements that suggest that our knowledge, although

\footnotetext{
${ }^{30}$ Given the incommensurability of perspectives, it would not make sense either to require that the empirical knowledge we form should be valid cross-perspectivally. The implicit correlate of Nietzsche multiperspectivism seems to be a form of empirical pluri-realism whereby different entities will be picked out according to different sets of transcendental features. Thus instead of 'the [metaphysical] true world' we should 'assert the existence of ' $x$ ' worlds (...). But this has never been asserted.' (WP §586).

${ }^{31}$ Although no human perspective would be possible without the use of transcendental features, there is more to the notion of perspective than just such use. As indicated by Poellner (following Leiter), knowing an object from a perspective also means knowing it 'from the standpoint of particular interests and needs' (Poellner 2001: 99). Thus although each specific perspective will by definition presuppose the use of the transcendental features prevalent at that particular time, the sort of objects it focuses on will depend on the interests of the representing individual.
} 
grounded in unavoidable beliefs, might nevertheless be or even is an 'error'. ${ }^{33}$ Such a claim is as ambiguous as it is problematic. If read literally, it threatens Nietzsche's own position in three different ways: firstly, as seen by most commentators, it creates a potentially fatal self-reference problem. Secondly, it seems to render Nietzsche's reinterpretation of Kant and his naturalisation of transcendental constraints into features rather pointless as it makes the resulting epistemology incapable of accounting even for the possibility of limited objective representations. Thirdly (as we shall see below), a literal interpretation of the error theory would require us to reintroduce precisely the sort of substantive ontological commitments which Nietzsche tried to distantiate himself from. Given these difficulties, the temptation is strong either to dismiss it, as Clark and Leiter suggest, or to minimise it as Nehamas does (Nehamas 1985: 51). ${ }^{34}$ I shall, however, resist both temptations and suggest that the error theory should not be taken literally but seen as a deliberately hyperbolic warning against naïve forms of realism and of transcendentalism, which in turn serves to reinforce the importance of Nietzsche's own naturalisation of the transcendental.

Before developing this argument, let us take a closer look at the literal interpretation of the error theory: it is fuelled by two separate arguments which both deepen Nietzsche's naturalisation of the transcendental. As seen by Stack, the first one rests on his use of evolutionary psychology. While he accepts that our experience presupposes certain a priori conditions without which it couldn't be the experience it is, Nietzsche now gives a Darwinian ${ }^{35}$, twist to such conditions: they are 'conditions of life', in the dual sense that they have evolved with our form of life, and are required for such life to maintain itself and develop. Thus if we establish what is necessary according to our current way of thinking, we have proved (...) only what "makes possible" our existence by virtue of experience - and this process is so ingrained that to try and turn thought away from it is impossible. Any a priori is located there' (KSA M III 1. Spring-autumn 1881 11[286], Nietzsche's italics). So while Kant started from experience and asked about the non empirical conditions that 'made it possible' in the transcendental sense, Nietzsche recontextualises such

\footnotetext{
${ }^{32}$ Cf. Poellner 2001; 88-98. All spatio-temporal objects have characteristics that mark them as represented (what he calls the 'essential representation-dependence thesis').

${ }^{33}$ For the weaker version of the error theory, see for example GS 121 ('life is no argument. The conditions of life might include error'); WP 483 ('a belief can be a condition of life and nonetheless be false'), 487 ('a belief, however necessary for the preservation of a species, has nothing to do with truth'), 497 (cf. main text), 515 (idem). For a stronger version, see HH I §11, BGE 4, 24; TI 'Reason in Philosophy', §5, WP 493 ('truth is the kind of error without which a certain species could not live'), 512 ('the will to logical truth can be carried through only after a fundamental falsification of all events'), 517 ).

${ }^{34}$ Thus the error theory would just express the lack of a God's eye perspective.

${ }^{35}$ As argued by Richardson (2004), most of the time Nietzsche is de facto in agreement with Darwin, and only rejects vulgarised versions of Darwinism.
} 
conditions within an evolutionary perspective and suggests ironically that having a certain form of experience (which does presupposes these 'a priori' conditions) is what 'makes possible' (in the causal sense, this time) human life, and was therefore evolved (along with its a priori conditions) so as to preserve and enhance such life. To put it plainly, we have become 'hard-wired' to use 'a priori' concepts and forms and to believe in the reality of the resulting objects; but the existence of such hard wiring is no guarantee for the truth of the resulting judgments. Thus 'it is high time to replace the Kantian question, "how are synthetic a priori judgments possible" by another question, "why is belief in such judgments necessary" — and to comprehend that such judgments must be believed to be true, for the sake of the preservation of creatures like ourselves; though they might, of course, be false judgments for all that!' (BGE I §11, Nietzsche’s italics). Another passage develops a similar idea: "the law of a priori causality - that it is believed may be a condition of existence for our species; for all this, it is not proved' (KSA 25 = W I 1. Spring 1885. 26 [74], Nietzsche's italics). ${ }^{36}$ The a priori conditions of possibility of experience are ultimately 'conditions of existence': their necessity is only relative to our need to believe in them, and their 'truth' only reflects the empirical conditions they result from. However, as such this argument is not decisive: it does not follow from this Darwinian naturalisation of the transcendental that our knowledge is false - and in many passages, including all the quotes given above, Nietzsche himself is careful to only suggest that it might be the case. All that follows is that it is not true in the absolute, universal sense that would be guaranteed by the existence of transcendental constraints.

The second argument for the literal interpretation of the error theory is grounded in a further naturalisation of the transcendental, this time through an analysis of language which naturalises the Kantian categories. Nietzsche does not dispute that such primary concepts as 'substance' or 'causality' are presupposed by the way we experience the world. Yet contrary to Kant (and in line with the spirit of his early argument in TL), he does not view such concepts as truly a priori: he traces their genesis to the existence of specific grammatical features present in all indoeuropean languages, in particular the subject/object structure and the active/passive modes (from which are respectively derived the notions of subject and substance on the one hand, and of causality on the other). Thus 'positing as "true a priori" our belief in the concept of substance (...) is simply a formulation of our grammatical custom which adds a doer to every deed' (WP 484); in other words, 'the concept of substance is a consequence of the notion of the [grammatical] subject'

\footnotetext{
${ }^{36}$ Cf. also WP497: 'the most strongly believed a priori "truths" are for me — provisional assumptions, e.g. the law of causality (...), so much a part of us that not to believe in it would destroy the race. But they are for that
} 
(WP 485). ${ }^{37}$ More generally, we are governed by our 'faith in grammar' (TI VI: 5; cf. also TI III: 5).

Nietzsche's point is not merely that whenever we speak of 'things' or 'subjects' or 'causes' we project onto reality grammatical structures which may be alien to it. The idea is that the very way we experience the world and individuate objects (prior to any verbal articulation), being structured by the categories, is ultimately shaped by the grammar of a specific and contingent set of languages. 'Our thinking itself involves this belief (with its distinction of substance, accident; deed, doer, etc). To let it go means: being no longer able to think' (WP 487). In a way that anticipates the linguistic turn in analytic philosophy, Nietzsche argues that the structure of our language shapes our perception of the world. We perceive what we take to be independently existing 'things', interacting causally with each other; but such perception only reflects the fact that our experience is made possible by concepts which themselves result from the unconscious reification of grammatical structures. Thus 'we have arranged for ourselves a world in which we can live — by positing bodies (...), causes and effects, motion and rest, form and content: without these articles of faith nobody now could endure life' (GS 121). Two points are worth noting: firstly, as above this naturalisation of the categories does not yield per se the conclusion that our knowledge is erroneous, but merely that its scope and nature are dependent on the kind of linguistic conditions that determine it. The fact that we only perceive causally interacting things does not mean, per se, that our perception is wrong: it just means that it is dependent on our use of causality as a category, which itself is due to a specific characteristic of our grammar. Secondly, in many quotes what Nietzsche seems to object most to is not so much our use of grammar (and thus the existence of transcendental features), which is unavoidable, as the fact that we are unaware of the assumptions and consequences of such use. As we shall see, this may point towards a more fruitful way of interpreting the error theory.

Still, there is no doubt that Nietzsche's naturalisation of the transcendental leads him to express skepticism about human knowledge. Yet as indicated above, none of the arguments provided yield per se the conclusion that all human knowledge is erroneous. For the literal interpretation of the error theory to validate such a conclusion, two additional premises are needed, namely a) that the world is otherwise than the way we construe it, and b) that our knowledge fails

reason truths? What a conclusion! As if the preservation of man was a proof of truth'.

${ }^{37}$ Cf. also WP 631: 'the separation of the "deed" from the "doer", (...) of the process from something which is not process but enduring substance, thing, body, soul, etc - the attempt to comprehend an event as a sort of shifting and place - changing on the part of a "being", of something constant: this ancient mythology established the belief in "cause and effect" after it had found a firm form in the functions of language and grammar'. 
to correspond to it. Whether this can be made good depends, in turn, on how premise a) is construed, i.e. on the nature of the allegedly falsified world: Nietzsche's texts lend themselves to two possible interpretations - phenomenological and ontological. Before offering in conclusion my own, non literal reading of the error theory, I shall now provide a brief reductio ad absurdum of these two possibilities by showing that neither of them can be accepted without committing Nietzsche to gross inconsistencies.

The first, phenomenological, candidate is what Nietzsche calls the 'fuzziness and chaos of sense impressions' (WP § 569): thus 'there is in us a power to order, simplify, falsify, artificially distinguish. "Truth" is the will to be master over the multiplicity of sensations' (WP §517). ${ }^{38}$ As indicated above, the idea is that we can only perceive a world which has been ordered into selfidentical, causally related spatio-temporal objects. This "world of "phenomena" is the adapted world which we feel to be real' (WP §569). But such reality is merely an illusion. By contrast, 'the antithesis of this phenomenal world is not the "true world" but the formless, unformulable world of the chaos of sensations (WP $§ 569$, my italics). This interpretation of the error theory does not rest on metaphysical assumptions about a mind independent reality to which our perception would fail to conform. It seems to be a new version of the idea already present in TL, according to which the use of concepts is per se falsificatory. In TL, the view was that concepts result from the equalisation of differences between various, non-conceptually formed, perceptual metaphors. Here, Nietzsche offers a reverse claim: the a priori use of concepts simplifies the primal stream of inchoate sense data which underlies conscious perception. Perhaps the best way to make sense of this idea is to think of it in Husserlian terms, and to suggest that such a primal stream of impressions could be understood as the 'hyle' of perception, 'sensation contents' (Ideen I, §85) which are associated through temporal and spatial syntheses (passive syntheses in Experience and Judgment), and actively unified into intentional objects through the 'sense bestowing' acts of the mind. However on Husserl's view such sensory contents are not truly sense data in the sense that they are not objects of awareness (this would require a noetic function); moreover, they are never given on their own (since we only apperceive intentional wholes for Husserl). They are a dependent aspect of conscious experience, which can only be approximated retrospectively, through introspection, and by means of such technical procedures as the epochê and the transcendental reduction. Yet try as we may, such reflective procedures can only give us access to synthetised unities. Thus while there may be such a

\footnotetext{
${ }^{38}$ Such a phenomenological reading is evoked, for example, by Granier 1977: 137, Wilcox 1974: 133, 149, and Stack 1991: 35.
} 
thing as a hyletic layer, it has no independent existence and cannot be described adequately, only evoked by contrast to higher intentional levels, in an abstract manner. Nietzsche's views seem close to Husserl in the sense that, as we have seen, he rejects the idea that we could be aware of raw sense data passively registering on the mind. Thus inner experience enters our consciousness only after it has found a language the individual understands' (WP §479). As in Husserl, such process has higher level layers: for us to experience something, 'it must be experienced as adapted, as "recognisable". The material of the senses adapted by the understanding, reduced to rough outlines, made similar' (WP §569). But there are also lower layers, which seem closer to the Husserlian passive synthesis of homogeneity: 'there could be no judgment at all if a kind of equalisation were not practiced within sensation' (WP §532). As in Husserl again (and presumably for the same reason), such a primary layer is inaccessible to consciousness: it is 'another kind of phenomenal world, a kind "unknowable" for us' (WP §569). Yet if this account is correct, then it is difficult to understand how the falsification thesis can hold (and Husserl certainly did not draw this conclusion from his account of perception). The reason is that presumably something can only be falsified if it can be said to exist independently, and to have identifiable intrinsic characteristics which are later distorted in such a way that through comparison with the original, we could pinpoint the falsification. Yet neither on Nietzsche's account nor on Husserl's do the primary layers of perception exist on their own; moreover, given the way our minds work it would be impossible for us to know what they are, and therefore to judge whether and how they would have been falsified.

The second, ontological, candidate for what knowledge allegedly falsifies is the 'world of becoming'. ${ }^{39}$ According to Nietzsche, such a world 'could not, in a strict sense, be "comprehended" or "apprehended" or "known"; only to the extent that the "comprehending" and "knowing" intellect encounters a coarse, already created world, fabricated out of mere appearances but become firm to the extent that this kind of appearance has preserved life, only to this extent is there "knowledge" (WP §520). This second version of the falsification thesis both differs from and complements the previous one. It has in common the idea that our experience presents us with a world of idealities, the stability of which is made necessary by our practical needs: thus 'our needs have made our senses so precise that the "same apparent world" always reappears and has thus acquired a semblance of reality' (WP §521). The new element is that this time, the object of falsification is not immanent to experience anymore, in the way the 'chaos of sensations' was supposed to be. What is

\footnotetext{
${ }^{39}$ For ontological readings of the 'world of becoming', see Danto 1965: 89, 96-97), Grimm 1977: 30, 32, and Magnus 1978: 25, 169.
} 
falsified is a mind independent world, a Heraclitean world of perpetual flux, which changes so fast that nothing can even be said to be identical to itself ${ }^{40}$ : 'the total character of the world, however, is in all eternity chaos' (GS III $§ 109$ ). So the idea is now that there is a fundamental incompatibility between our sensory and conceptual apparatus on the one hand, and the 'real' world on the other. Thus 'logic too depends on presuppositions to which nothing in the real world corresponds, for example on the presupposition that there are identical things, that the same thing is identical at different points in time'41 (HH I §11). The result of such falsification is an imaginary world of spatio-temporal objects, causes and effects, which we wrongly believe to be real: "reality" is always only a simplification for practical ends, or a deception through the coarseness of organs' (WP §580). However, the problem with this reading is that its intrinsic dualism (which contrasts the world of stable appearances with the 'real' world of becoming) seems to rest precisely on the sort of ontological commitments rejected by Nietzsche. It is difficult to see how such a world, which supposedly has an independent existence and can only appear to us through the simplifications of our minds, and is thus deemed by definition 'unknowable', is different from the in-itself criticised by Nietzsche. On this interpretation then, later Nietzsche would end up in a worse position that his younger self, since at the time of TL he refrained from making any assumptions about the nature of the 'mysterious X', and pointed out against Schopenhauer that none of the concepts or categories used to structure empirical experience could be applied to it. Yet if the 'real' world is identified with the world of becoming (i.e.: a concept of empirical origin), Nietzsche would be making both these mistakes, which seems strange given the care he has taken to move away from the ontological assumptions of transcendental idealism. The only way out of this dilemma is to move away from metaphysical commitments and to understand the world of becoming as a mind independent empirical world. Thus Cox claims that the world of becoming is 'the world we inhabit and know: the natural, physical world, the world of "appearance" (Cox 184). He asserts that this world is 'empirically evident' (188), that it is the 'physical, natural world that we inhabit and with which we

\footnotetext{
${ }^{40}$ (One may argue, along Kantian lines, that on such a construal, it would be impossible for us to notice any changes, or even to have the concept of change. For unless something can be said to change, we would be unable to identify any modifications in the flux of becoming, and thus to even have a notion of becoming). ${ }^{41}$ See also: 'without a constant falsification of the world by means of numbers, man could not live' (BGE I §4), or again 'the will to logical truth can only be carried through only after a fundamental falsification of all events is assumed' (WP §512). Some interesting insights about Nietzsche's views on logic can be found in Hales \& Welshon 2000, p. 43 sq. The authors argue that while syntactic logic, which provides the rules for the manipulation of the operators, connectives, quantifiers etc. of a formal system, does not need such presuppositions, semantic logic, which specifies domains of entities, does. Thus 'in order for the symbols and formulas of logic to mean anything or have any applicability, there must be sets of things to which they refer' (Hales \& Welshon 2000: 43).
} 
are familiar' (193) and which must be understood with reference to Heraclitus. Yet this option seems very counter-intuitive, not to say implausible: one would think that the very point of Nietzsche's claims about the world of becoming being chaotic and incomprehensible is to bring out the fact that there is nothing 'empirically evident' or familiar about it. What is empirically evident is precisely its opposite, i.e. the world of stable objects we encounter in experience, and which Nietzsche contrasts with the 'real' world.

Thus the literal reading of the error theory, whether construed phenomenologically or ontologically, is met with insurmountable difficulties. Yet perhaps something valuable can be gleaned from this failure: it may be taken as an indication that the problem, in this case, lies with literalness itself. I shall therefore turn to a non literal construal which, I should hasten to say, is intended as a tentative answer only: the incompatibility of some of the passages cited removes the possibility of a univocal solution to the epistemological quandary resulting from the error theory. My hypothesis is that the real target of Nietzsche's skepticism about knowledge may not be so much the possibility of limited objectivity resulting from the use of perspectival conditions as two kinds of illusions: on the one hand, our inclination, motivated by the drive for survival, to ignore the fact that our experience is determined by transcendental features, which results in metaphysical realism or in naïve empirical realism; on the other, the tendency of some philosophers (in particular Kant) to take what is merely features for constraints, and to think that universal and necessary knowledge is possible, when in fact only relative forms of objectivity are legitimate. To use the vocabulary of the quotes given above, the problem may not be so much with our having a grammar, or with the world we experience according to it, as with our lack of awareness of such grammar and our blind 'faith' in the mind independent reality of the entities that surround us and which we instinctively 'feel to be real' (WP §569). In that case, we should not read the 'world of becoming' literally, as an expression describing the true state of the world, but metaphorically, as pointing towards an irrepresentable object. The function of such an object would not be to serve as a problematic referent for the falsification thesis, but to make us reflect both on the workings of our own minds and on our assumptions about the empirical world: the irrepresentability of the 'world of becoming' draws our attention (a contrario) on the fact that both perception and the perceived objects are structured by some naturalised transcendental features, without which no representation is possible. By pointing toward the limits of human representation, it allows its structural conditions to emerge for reflection. 
This suggestion has the advantage of minimising the self reference problem and of complementing the main strands of Nietzsche's thought previously identified: his qualified endorsement of transcendental determination, his naturalisation of transcendental constraints into transcendental features, and his deliberate agnosticism about ontological commitments. It is clearly compatible with, and helps make sense of, the weaker formulations of the error theory; as for the stronger formulations, they can more fruitfully be regarded as a deliberately hyperbolic rhetorical device meant to signal that what is problematic is not so much the existence of such transcendental features (after all they are just the expression of our finitude), but the fact that we have a natural tendency to be unaware of their existence. We tend to behave either as metaphysical realists, i.e. as if our knowledge was unconditioned and we had direct access to the in-itself, or as naïve common sense realists, i.e. as if we could just encounter pre-existing, mind-independent objects in the world, without realising that there is an a priori (in Nietzsche's revised sense) agreement between the structure of such objects and the conditions under which we know them, and that therefore such objects are constituted, not found. In other words, the real target of the error theory would not be the possibility of (limited) knowledge itself, but a certain naiveté about its scope and its objects. This warning is clearly expressed in the following passage: 'our knowledge is no knowledge in-itself (...). It is our own laws that we project in the world - even though appearance teaches us the opposite and seems to point towards us as consequences of this world, and to point towards these laws in their action upon us' (KSA, M III 1. Spring-autumn 1881 15[9], my italics). Given the ineluctability and the strength of the 'teaching of appearances', we need the stronger formulations of the error theory to help us resist our natural tendency to believe in the pre-existence and independence both of the empirical world (of which we appear to be 'consequences') and of its laws. What we must beware of is not so much the conditioned character of our knowledge as our ignorance of the 'poetico-logical power' from which it results, and by 'virtue of which we keep ourselves alive' (KSA III 1. Spring-autumn 1881 15[9]): 'it is we alone who have devised cause, sequence (...) and when we project and mix this symbol world into things as if it existed 'in-itself, we act once more as we always have acted - mythologically'(BGE I §21, Nietzsche’s italics). On the reading I suggest, the error theory points out that the problem is not so much the projection, since it is constitutive of the way human experience works, as our lack of awareness of our own activity, and our corresponding belief in the independent existence of the projected.

If this is right, then it becomes possible to interpret Nietzsche's views on knowledge in a way which does not make it self-undermining, but on the contrary brings out two interesting 
aspects: firstly, the intertwining of naturalistic and transcendental aspects in his account of the formation of human experience, which culminates in the notion of naturalised a priori conditions (transcendental features) and makes it impossible (contra both Green on the one hand, Clark, Cox and Leiter on the either) to define him either as a transcendental philosopher or as a naturalist. In this, Nietzsche anticipates on later Continental philosophers such as Foucault, who shares both his anti-empiricist assumptions about the constitution of experience and his skepticism about the possibility of truly necessary, universal a priori constraints. The Foucaldian notion of a historical a priori, rooted in and yet distinct from contingent historical practices, presents a similar ambiguity (and interest) as Nietzsche's own naturalisation of the transcendental in that both its necessity and its scope are dependent on practices to which it is, however, not reducible, and which presuppose its existence be intelligible. The second important aspect resides in the highly critical dimension of Nietzsche's thought, which manifests itself at two distinct levels: ontologically speaking, through his rejection of the formerly endorsed robust, two-world version of transcendental idealism in favour of a minimalist, perspectivist ontology according to which it makes no sense to talk about things-in-themselves, let alone to attribute them a self-standing essence. All that can be said is that should our own perspectival conditions be bracketed, it is possible that others would apply, according to which different, incommensurable worlds would be constituted. But what they apply to could not be defined independently from these other perspectives, and thus could not be said to have any essence in-itself: reality is perspectival through and through. Moreover, while this possibility has to be acknowledged, one must be more cautious than Kant himself was and remain agnostic about the actual existence of such conditions and worlds. In Kantian terms, the critical impact of Nietzsche's thought here is that the status of the ontological commitments of transcendental idealism must be considered as problematic, not assertoric (let alone apodictic). Epistemologically speaking, this critical dimension is expressed by the role played by his so-called error theory. As we have seen, part of the thrust of his naturalisation of the transcendental is to emphasise the fact that a priori conditions do not have any rational validation, but are entailed by practices which are necessary for the survival of our species. Thus in order to preserve and develop their lives, human beings have to believe in the existence of an ordered, relatively stable world of mind-independent entities, with which they can interact causally, and on which they can act and obtain results with a sufficient degree of predictability. Correlatively, we instinctively tend to view knowledge as the non perspectival identification of the properties of such pre-existing entities. On this background, I have argued that the function of the error theory is not to suggest that there is 
something wrong with perception, or that the perceived world is fictitious, but to draw our attention to the dependency of both on naturalised transcendental conditions. It is not so much an error theory stricto sensu as a hyperbolic warning against uncritical forms of realism. It is not aimed against the possibility of a statement being true within a set of perspectival conditions, but rather at a set of implicit beliefs: that there are no such conditions (naïve realism), or that our statements can be true of all possible perspectives (which would require the existence of universal transcendental constraints), or worse, extra-perspectivally (by virtue of metaphysical correspondence). Thus the error theory is meant to counterbalance our hard wired tendency to be naïve realists about the world and about knowledge. ${ }^{42}$ While such a tendency cannot be eradicated (precisely for the sort of naturalistic reasons pointed out above), it is possible to limit its effects in two ways: on the one hand, by exposing it, although in order to do so one will have to constantly fight against our nature - hence the deliberately hyperbolic character of the error theory. On the other, by openly indexing one's own statements to their conditions of possibility (hence Nietzsche's constant emphasis on the perspectival aspect of his claims). Thus what makes Nietzsche's views on knowledge particularly interesting, in my view, is that while they clearly very strongly influenced both by transcendental and naturalistic concerns, they present a position which tends to overcome the opposition between the two trends while taking up one of the most valuable insights of the Kantian legacy, namely its critical spirit.

\author{
Béatrice Han-Pile \\ University of Essex \\ Philosophy Department
}

\footnotetext{
${ }^{42}$ Thus it is meant to deter us from adopting precisely the sort of 'common sense realism' advocated by both Clark and Leiter. In this regard, the thrust of Nietzsche argument is to suggest that such realism is far from being devoid from metaphysical assumptions about the nature of reality. It impliciTL:y relies on the claim that empirical objects are mind-independent and have intrinsic properties which can be defined independenTL:y from the way we access them. Leiter's gloss of the well known passage about perspectivism in GM III $§ 12$ is illustrative of this belief: 'consider a useful analogy. If we wanted to get knowledge of a particular geographic area by making a map of it, the kind of map we would make would necessarily be determined by our interests. (...) The map corresponding to each set of interests would give us genuine knowledge of the area, and the more interests embodied in maps, the more we would know about the area.' (Leiter 2002: 273-4). The striking thing about the analogy is that it presupposes that the area to be charted by the various perspectival maps (i.e.: the real) pre-exists to and is independent from the charting itself, which is exacTL:y the sort of naïve belief Nietzsche warns us against by means of the error theory.
} 


\section{BIBLIOGRAPHY:}

\section{Works by Nietzsche:}

TL:: 'Truth and Lies', in Philosophy and Truth: Selections from Nietzsche's Notebooks of the Early 1870's, D. Breazeale ed., London : Humanities Press, 1979.

KSA: Nachgelassene Fragmente, Herbst 1869 bis Herbst 1872. Berlin: Walter de Gruyter, 1978.

HH: Human, All Too Human, transl. R. J. Hollingdale, Cambridge: Cambridge UP, 1968.

GS: Gay Science, trans. W. Kaufmann. New York : Vintage books, 1974.

BGE: Beyond Good and Evil, transl. W. Kaufmann. New York : Vintage books, 1989.

GP: Genealogy of Morals, transl. W. Kaufman, New York: Vintage books, 1967.

TI: Twilight of the Idols, transl. R. Polt. Hackett Publishing: Indianapolis, 1997.

WP: The Will to Power, transl. W. Kaufmann, New York : Vintage books, 1968.

\section{Commentators:}

ALLISON, Henry, Kant's Transcendental idealism: an Interpretation and Defense, New Haven \& London: Yale UP, 1983.

BIRD, Graham, Kant's Theory of Knowledge, London: Routledge, 1962.

CLARK Maudemarie, Nietzsche on Truth and Philosophy, Cambridge: Cambridge UP, 1990. Also, 'The Development of Nietzsche's Later Position on Truth', in Nietzsche, J. Richardson and B. Leiter eds, Oxford: OUP (Oxford Readings in Philosophy), 2001, p.59-84.

KOFMAN Sarah, Nietzsche and Metaphor, transl. Duncan Large, London, Athlone Press, 1993.

COX Christoph, Nietzsche : naturalism and interpretation, Berkeley : University of California Press, 1999.

DANTO Arthur, Nietzsche as a Philosopher, New York: Mc Millan, 1965.

DE MAN Paul, Allegories of Reading : Figural Language in Rousseau, Nietzsche, Rilke, and Proust, New Haven : Yale University Press, 1979.

DERRIDA Jacques, Spurs : Nietzsche's Styles, transl. Barbara Harlow, Chicago : University of Chicago Press, 1979.

GRANIER Jean, 'Nietzsche's Conception of Chaos', in D. Allison (ed), The New Nietzsche, Cambridge: MIT Press, 1977.

GREEN Michael, Nietzsche and the transcendental tradition, Urbana and Chicago: university of Illinois Press, 2002. 
GRIMM Rüdiger, Nietzsche’s Theory of Knowledge, Walter de Gruyter, 1977.

HALES Steven and WELSHON Rex, Nietzsche's Perspectivism, Chicago: University of Illinois Press, 2000.

LEITER Brian, Nietzsche on Morality, London: Routledge, 2002. Also, 'Perspectivism in Nietzsche's Genealogy of Morals', in R. Schacht (ed.), Nietzsche, Genealogy, Morality (Berkeley: University of California Press, 1994).

MAGNUS, Bernd: Nietzsche’s Existential Imperative, Indianapolis: Indiana UP, 1978.

POELLNER Peter, Nietzsche and Metaphysics, Oxford: Clarendon Press, 1995. Also, 'Perspectival Truth', in J. Richardson and B. Leiter (eds.), Nietzsche, (Oxford: OUP (Oxford Readings in Philosophy), 2001, p. 85-117).

RICHARDSON John, Nietzsche's new Darwinism, Oxford : Oxford University Press, 2004.

SACKS Mark, Objectivity and Insight, Oxford: Oxford Clarendon Press, 2000.

STACK George, Lange and Nietzsche, Berlin ; New York : W. de Gruyter, 1983. Also, 'Kant, Lange and Nietzsche: Critique of Knowledge', in Nietzsche and Modern German Thought, Keith Ansell-Pearson ed, London: Routledge 1991, p. 30-58.

STRAWSON Peter, The Bounds of Sense: An Essay on Kant's Critique of Pure Reason, London: Methuen, 1966.

WILCOX John, Truth and Value in Nietzsche: A Study of His Metaethics and Epistemology, Ann Arbor: University of Michigan Press, 1974. 